\title{
THE FRESHMEN'S ABILITY ON USING THE GRAMMAR OF ENGLISH IN ACADEMIC YEAR 2019/2020
}

\author{
Viator Lumban Raja \\ Catholic University of Saint Thomas \\ Email : viator_lumbanraja@ust.ac.id
}

\begin{abstract}
Grammar is the rules of how words are arranged into sentences. Without the knowledge of grammar one cannot produce sentences grammatically. If one makes a sentence which is not grammatically arranged, then that sentence cannot be said grammatical though perhaps it is still meaningful. Therefore, a sentence should be grammatically correct and meaningfully acceptable. This study deals with the ability of the freshmen of the English Study Program on using English grammar in academic year 2019/2020. They are first given the pretest, and after studying for one semester they are given the posttest in order to see if there is significant difference from the pretest to posttest. It is expected that the learning-teaching process for one semester will give significant impact on the learning achievement. Based on the result of analysis of the test both in the pretest and posttest, it is found out that there found no difference between the result of the pretest and that of posttest. It is indicated by the mean score of the pretest 9.04 and that of posttest only 9.00. Therefore, it can be concluded that their ability on using English grammar is far below the average as the percentage of correct answer only $30.10 \%$ both in the pretest and posttest. Of the 17 topics covering the 30 test items both in the pretest and posttest, only 5 (five) items are correctly answered by more than 10 students within the percentage of $44 \%$ - $68 \%$. On the whole,. Their ability on using English grammar is far below average.
\end{abstract}

\section{A. Introduction}

Every language has its own grammar, namely rule of how words are arranged into sentences. Words or group of words cannot be arranged at will but they must follow certain rules; otherwise, they will produce bad grammar. A sentence can have a good structure but bad grammar. Therefore, one should understand the difference between grammar and structure though they may sometimes be overlapping.

It is needless to say that one should have a mastery of the grammar of a language if he studies that language. Otherwise, he will produce a lot of ungrammatical sentences which are considered bad grammar. Therefore, the grammar is something inevitable in learning a language because it is the core of that language. Without grammar mastery, it is quite impossible to expect that someone can produce good sentences which are easy to understand.

Talking about structure, it refers to a sentence pattern. Sentences are made based on a certain pattern, besides being grammatically correct. Thus, a sentence should cover a least two things, based on the certain pattern, and correct grammar.

(1) I only saw him once after that.

(2) He did carefully his homework.

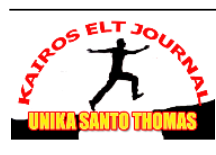


As for these two sentences, there is nothing wrong with the grammar but the structure of the sentence pattern. Both sentences have fulfilled the grammar but they are not well organized, they should be organized as follows:

(1a) I saw him only once after that.

(2a) He did his homework carefully.

In sentence (1a) the adverb only modifies the adverb once which indicates a frequency or qualifier referring to the adverbial of time. The position of only is not after subject because it does not modify the subject, but another adverb. When sentence (1a) is written as "I just saw him only once after that", then the adverb just modifies the verb saw, and this still has good grammar and structure.

In sentence (2a) the adverb carefully should come after direct object, not the verb did though it does not modify noun, but verb. It is also possible to construct that sentence by moving the adverb to the beginning of the sentence, "Carefully, he did his homework."

In the English Study Program, this subject is called structure given right from the first semester up to the fourth semester. Totally, there are ten credits of this single subject for the whole academic year. In the first semester, it is given four credits, and in other following semesters it is given two credits respectively.

However, whether the students in fact have a mastery of English grammar it has never been known. In regards to this, it is of great prominence to know the entry behavior of the Freshmen of English Study Program on English Grammar. What do they really know about English grammar? Do they have sufficient mastery of English grammar to join the English Study Program? Therefore, they will be given Pretest on English grammar before commencing lecture in academic year 2019/2020. Then after the learning - teaching process for one semester, they will be given the Posttest with the same test. Later, the result of Pretest and that of Posttest will be compared to find out if there is a significant difference between the two.

\section{Problem Identification}

Based on the writer's experience for teaching over thirty years, there has been no accurate entrance test for the candidates of students in every new academic year. What has been done so far to select the candidates is to look at the final report of their final grade in Senior High School, and to make a short interview for some study programs.

For that reason, it is not clearly known how the entry behavior of the candidates is so that it is quite suspicious that they have inadequate background of English to join the English Study Program. This is also proved that the result of the previous students' semester examination is not very satisfactory.

In accordance with the background and problem identification, the problems of the study can be formulated as follows:

a. Is there any significant difference between the result of pretest and that of posttest?

b. Is there any significant difference between the result of pretest of state school students and that of private school students?

c. Is there any significant difference between the result of posttest of state school students and that of private school students?

d. What aspects of English grammar do the freshmen not understand most 


\section{B. Grammar}

Every language has its own grammar in order to produce correct sentences which lead to understandable communication. Without grammar, it is unlikely to produce good sentences correctly. In other words, a communication is hard to comprehend without sufficient grammar. Grammar is a rule of how sentences are arranged. Here below it is presented kinds of grammar

\section{Traditional Grammar}

In the past, they study of language was related to the Latin language which emphasized the terminology of language such as noun, verb, adjective, subject, predicate, direct object, etc. Traditional grammarians tried to prescribe how the language should be used according to grammatical rules which is based on Latin language. They believed that only the standard form of the language should be used and that all other forms were inferior (Seely, 2000: 149). They worked on the assumption that this was a standard grammatical structure which could be applied to all languages. But all languages work on different ways and different grammar. As a result, the attempt to impose a Latin grammar on English way is not a success. 2. Descriptive Grammar

Since there are a lot of language phenomena which cannot be accounted for by traditional grammar, a modern descriptive grammar emerges due to dissatisfaction of traditional grammar. This grammar produces rules which explain how things work not what things should be done. In other words, descriptive grammar describes how a language is used in reality; not what should be used with a language.

Richards, et.al (1985: 125) state that grammar is a description of the structure of a language and the way in which linguistics units such as words and phrases are combined to produce sentences in the language. It usually takes into account the meanings and functions these sentences have in the overall system of the language.

$$
\text { e.g (1) } \frac{\text { They }}{\mathrm{S}} \frac{\text { walk }}{\mathrm{P}} \frac{\text { to school. }}{\mathrm{Adv}}
$$

Sentence (1) is a grammatical sentence according to both traditional and descriptive grammar. The meaning of the sentence can be well understood.

(2) My brother is pregnant.

$$
\mathrm{S} \quad \mathrm{P} \text { SA }
$$

Despite the fact that sentence (2) is grammatical and each word or phrase has a clear function, it cannot be semantically acceptable because the feature of the word pregnant is contrary to the fact in which a male cannot be pregnant but a female can. To conclude, a good sentence must be grammatically correct and semantically acceptable.

Grammar is an explicit system of elements and rules needed to form and interpret sentences. All languages have a grammar consisting of the linguistic components such as phonetic, phonology, morphology, syntax and semantics (O'Grady and Michael, 1989: 4). Therefore, the speaker of a language must have known the grammar of his language because all language use requires knowledge of sound pattern, rules for word and sentence formation, and principles of semantic interpretation. It is clear that this knowledge is not acquired through formal education, but it is a subconscious knowledge of the speaker of a language. 
Veit (19896: 6) supports the idea above by saying that a grammar is a person's subconscious language knowledge. It consists of principles or rules that allow someone to create an infinite number of possible sentences out of a finite number of words. In short, grammar is one's language knowledge.

Of these four words: no, monkeys, have, words, we can produce the following sentences though some may have nonsense meaning.

No monkeys have words.

Monkeys have no words

Have monkeys no words?

Have no monkeys now words?

No words have monkeys.

Have no words, monkeys!

Some of these combinations are unusual, some perhaps even silly but they are all grammatical sentences. Perhaps there are more combinations of these four words that would constitute English sentence, but not every possible combination is grammatical.

*Words monkeys have no.

This is an ungrammatical sentence because such a pattern is not recognized as an English sentence pattern. Our ability to arrange words into different ways allows us to produce an infinite number of grammatical sentences, but since not all arrangements are grammatical, the grammar must consist of principles or rules for arranging them.

A sentence is considered grammatical if speakers judge it to be a possible sentence of their language (O'Grady and Michael, 1989: 126).

e.g (1a) * house painted student a the.

This sentence is not a possible sentence in English although the same words can be combined in a different way to form the grammatical structure.

(1b) A student painted the house. Or, The student painted a house.

This is a possible sentence in English because the particle should precede a noun.

The difference between grammar and structure can be seen in the following sentences (Fitikides, 1963).

The teacher often sits on his desk.

The man was absorbed at his work.

I have no any mistakes in dictation.

He behaves friendly.

All the four sentences above have problem with grammar. Sentence (1) and (2) have problem with preposition. The verb sit employs preposition at when it is followed by the noun desk, table, however, "sit on a chair". Likewise, adjective absorbed is followed by preposition in, not at. In sentence (3) the word any should be dropped to make it meaningful. Sentence (4) is not correct since the word friendly is an adjective which cannot modify the verb behaves. Therefore, those sentences should be revised as the following:

(1a) The teacher often sits at his desk.

(2a) The man was absorbed in his work.

(3a) I have no mistakes in dictation. Or I do not have any mistakes in dictation.

(4a) He behaves in a friendly manner.

As such it can be said all these sentences contain grammatical mistakes because they do not fulfill the rules of the language.

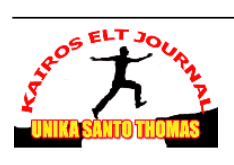


The next five sentences below have problem with structure.

I only saw him once after that.

Is the room enough large for you?

He wrote carefully his exercise.

Why you were absent last Friday?

All people are not hard-working.

All these five sentences have correct grammar but they are not correctly structured or arranged. Below is the revision of those five sentences above.

(1a) I saw him only once after that.

(2a) Is the room large enough for you?

(3a) He wrote his exercise carefully.

(4a) Why were you absent last Friday?

(5a) Not all people are hard-working.

\section{Standard and Non-Standard Grammar}

The term standard and non-standard English in the first place refer to social group with different class. Standard English is used by middle class people with high education, and non-standard English by low class people with low education, especially those who live in the ghetto in the United States.

As a matter of fact, all language show internal variation because language is not fixed from group to group, speaker to speaker, the choice of words, and even the use of syntactic structure.

(1) You makin' sense, but you don’t be makin'n sense (Akmajian, et.al 1991: 229).

Looking at this sentence above, speakers of standard dialect of English are likely to conclude that this sentence is ungrammatical. The first clause lacks a verb (finite) that the standard dialect requires, and $d o+b e$ in the second clause is a combination that the standard dialect prohibits. However, these two sentences are grammatical in its dialect (dialect of Black English). It represents one of the many variations in form that English can take. The first clause states the action is taking place (progressive form) while the second clause states the habit. In formal English they can read: "You are making sense now, but you usually don't". There is a thorough explanation about the form of those two sentences according to Black English grammar.

Akmajian et.al (1991: 234) continues that a dialect is simply a distinct from of languages, possibly associated with a recognizable regional, social, or ethnic group differentiated from other forms of language by specific linguistic features like pronunciation, vocabulary, and grammar. In the United States at present, standard American English is a form of the language used in news program in the national media, it is the language of legal and governmental functions; and it is the language used in school as a vehicle of education.

Therefore, one cannot claim that their English is not standard because language use is different depending on the context. Language use in a conference, office, is different from that in the market place, in other states, and in coffee shop. Even people in the United States and people in Britain speak the same language but with important difference of vocabulary and grammar.

e.g 1 a. He lives in the flat (British)

b. He lives in the apartment (American).

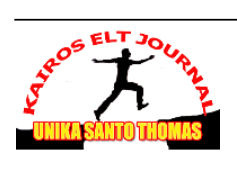


2 a. Have you got to go ? (British)

b. Do you have to go? (American)

3 a. What he want? (Black)

b. There ain't nothing matter (Black)

These are only some examples to show how English is used by different speakers with some differences in vocabulary, grammar and sentence construction.

\section{Sentence Structure}

A sentence is a group of words with a complete meaning and consists of at least a subject and predicate. These words are structurally organized to become a sentence. The organization of the words follows certain rules which describe how these words are arranged. This is what we call syntax which explains why these sentences below have different or similar meanings:

(1) The cat sat on the mat.

(2) The mat sat on the cat.

(3) John wrote a letter.

(4) A letter was written by John.

Sentence (1) and (2) have different meaning because the subject is different, however, sentence (3) and (4) have similar meaning though the form is different and the subject is different.

A sentence must contain a complete or finite verb which indicates tense, number and person. It consists of a t least a subject and predicate, categorically NP + VP (Seely, 2000: 154). On the other hand, O'Grady and Michael (1988: 135) enhance that each category can itself consist of other categories. Wekker and Haegeman (1996: 21) state that sentences are hierarchically organized into different constituents. They have structure but they are not just string of words which occur in a random order. The words do not just follow each other like the beads on a string but they are strictly organized internally. There is an underlying pattern.

(1) He phoned the girl from the library.

This sentence has grammatical ambiguity because the phrase from the library may function as an adverbial or modifier to the head girl. It can be described through the following tree diagram.

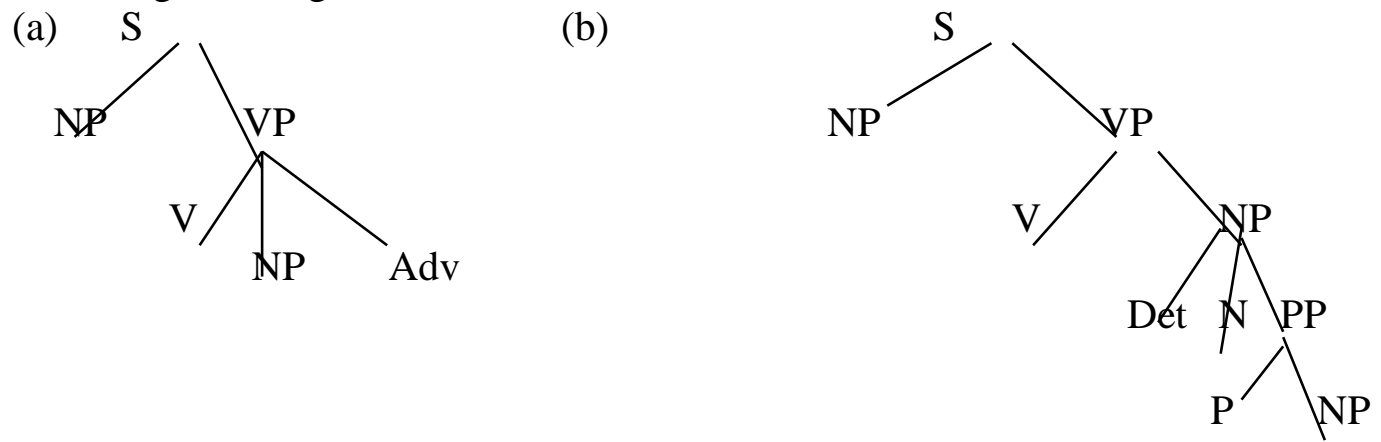

Tree diagram (a) describes that $\mathrm{He}$ phoned from the library, functioning as adverbial. Whilst tree diagram (b) the phrase from the library does not function as adverbial, but modifier as it modifies the noun phrase the girl.

Structural ambiguity is the grouping together of words into phrases which reflect not only the syntactic organization of the sentence but also the way in which word meanings are combined together to give the meaning of the full sentence (O’Grady and Michael, 1989: 135).

(2) fast cars and motorcycles

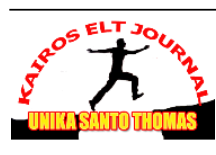



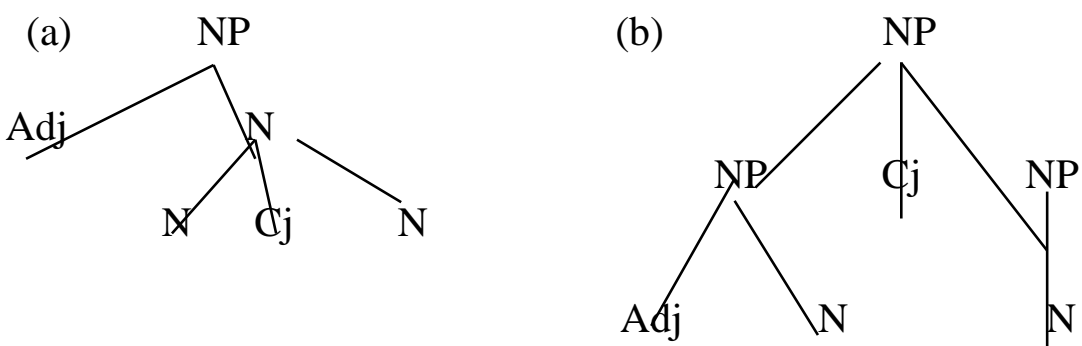

Tree diagram (a) says that both vehicles are fast, but tree diagram (b) says that only cars are fast, motorcycles are not.

Sometimes the structure of sentences is too complicated to understand despite the fact that it is grammatical. Therefore, it is advisable that the structure of sentence is simple, clear in addition to being grammatical.

(3) Michael Jackson whose childhood was full of hardship and was badly treated by his own father was the king of Pop Song whom most American teenagers adored very much.

(4)The teacher who the man whom the children saw talked to is a cousin of Joan's.

Both sentence (3) and (4) are grammatical sentences because they can be generated by the rules of grammar. However, they can be regarded as unacceptable as the structure is to complicated which make them difficult for a listener or reader to understand easily.

In conclusion, it can be said that structure refers to sentence pattern with category and function whereas the grammar refers to the rules of language. Category covers noun phrase, verb phrase, adjective phrase, adverbial phrase and prepositional phrase, whereas function covers subject, predicate and complement which can be divided into several functions.

\section{Research Design}

This research is called one group pretest-posttest design which involves three steps: (1) administering a pretest before the semester instruction begins,(2) administering a posttest after one-semester of instruction, (3) this instruction is a regular one, not involving a certain method or a new strategy in teaching a certain subject. It is assumed that a good instruction will reach the stated instructional objectives, the learning achievement . To make it easier, here below is presented the design of the research.

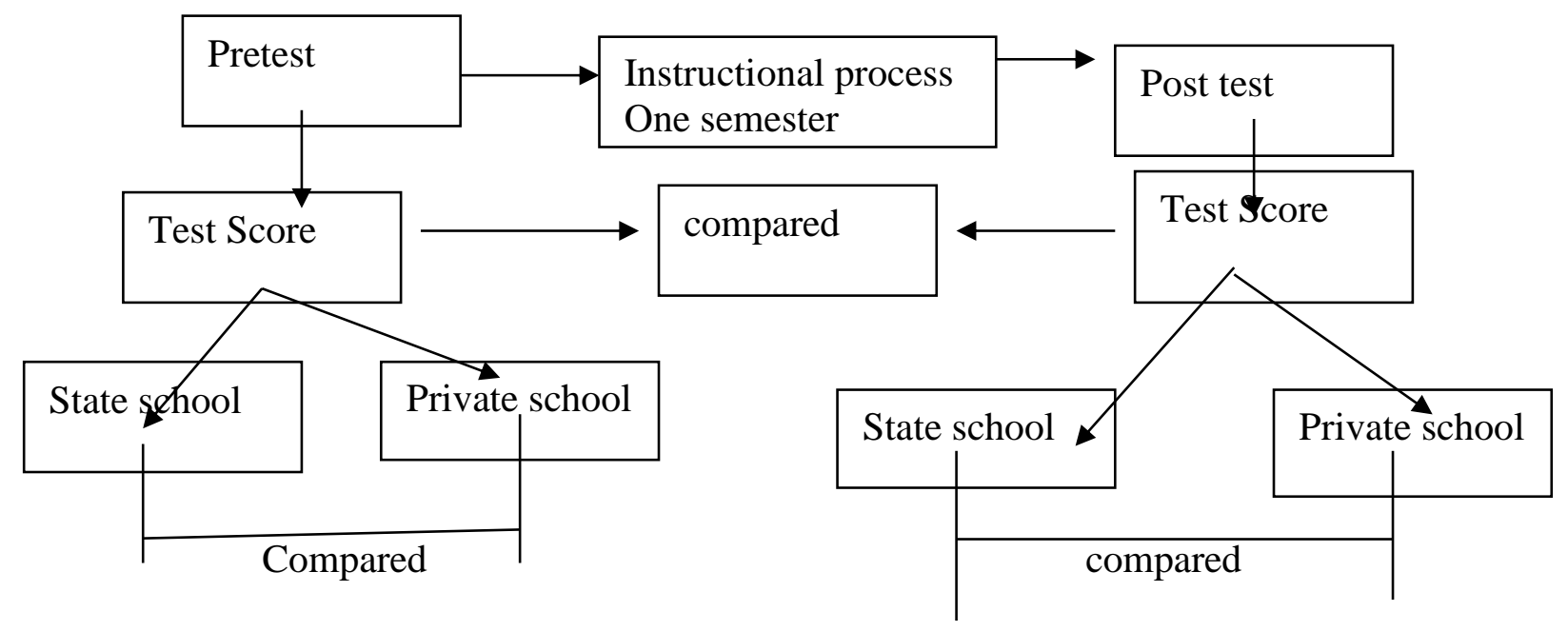


This research is conducted at the Faculty of Teachers Training and Education Catholic University of Saint Thomas in September 2019 before the lectures start. The population and sample are freshmen in academic year 2019/2020 of English study program with 25 students because this research is intended to find out whether there is a significant difference of learning achievement before and after taking lectures in the first semester. They are given pretest, and the result will be compared to that of posttest after they have completed the semester program.

1.The Result of the Pretest and Posttest

The pretest was administered in September 2019 before the new students started the odd semester 2019/2020. Of 30 test items in multiple choice form, no student can reach $50 \%$ of the total test items. There are only six students $(24 \%)$ who could achieve $40-43 \%$ of the test, that means they can answer only 12 to 13 test items correctly. The rest are below $36 \%$ of the total test items which means that they can answer only 11 test items correctly or below. This is really far from being satisfactory. The total score of the pretest is 226 with the mean score 9.04.

What can be drawn from the result of the pretest is that all the students have inadequate command of the English grammar because nobody can reach up to $50 \%$ correct of the test items though the good command of the English grammar should reach $70 \%$ minimally of the total test items. From the result of this pretest it is clear that these students have poor knowledge of the English grammar. This implies that the lecturer who teachers this subject should work harder to make them have something of the English grammar.

After one semester of instruction, it is definitely expected that the result of the test is far better that the previous one. The posttest is administered on January 14, 2020. The test is similar to the one administered in the pretest without any changes or revision. The result, however, is far of expectation because it does not show any improvement. The total score is only 225 precisely the same as that of the pretest which makes the mean score exactly 9.00 where as the mean score of the pretest is 9.04. The difference of mean score between the pretest and posttest is only 0.04 which means insignificant. How this can happen requires another study to find out why after studying for one semester does not show any improvement in the learning achievement compared to the one before studying the subject.

That there is no difference of the result between the pretest and posttest becomes a big question to the writer or to the readers. The apparent answer to such a question is that the students do not get anything during the learning-teaching process for one semester. They have not learned yet because there is no behavioral change from the state of not knowing to the state of knowing. In other words, the process of learning-teaching for this subject is questionable since there is no change or improvement of the test score after learning for one semester. Other questions may arise: (1) what material is given to the students for English grammar or structure? (2) how are they taught? what is the learning-teaching process like? (3) are the topics given in the classroom different form those administered in the pretest and posttest? (4) Do the students have no motivation in learning?

Question (1) and (3) are nearly the same, and topics given in the pretest and posttest are similar, among others: pronoun, adverb, possessive, tense participle, passive, etc. As it is has been said in chapter three, there are 17 topics given in the test, and each topic consists one or two items, except about adjective and conditionals which consists of four test items respectively. Nearly all the topics 
must have ever been given during their senior high school, and then they must be repeated during their semester program once or twice. Therefore, these topics are not really new, except causative, perhaps. The problem now is how they are presented to the students that they cannot do the test after one semester program. This means that their learning is useless because it does not show any increase or improvement on their mean score of the test. Both the mean score of pretest and that of posttest remain. Thus, the learning has no impact on their score because the result does not change. Theoretically, the result of the posttest should be better than that of pretest because of the learning. As a consequence, the learning-teaching process needs reviewing since it should give impact on the test result after the pretest was given. In this case, the result of pretest and posttest remains the same, that indicates the learning teaching process does not work well as it is expected.

2.The Percentage of Correct Answer

The result of both pretest and posttest does not show any improvement. In the pretest, no students achieve $70 \%$ correctly of the test, and that means no one belongs to category good because category good implies that a student can answer correctly $70 \%$ of the total test. Thus, if there are 30 item tests, a students should answer 21 test items correctly to be called good category. The fact is these students ( 2 students) can only answer 13 test items (43\%) correctly. The rest are below $43 \%$ or lower than 13 test items correct out of 30 test items. This result indicates that the students have very poor command of English grammar. In other words, their English background is inadequate to join the English study program. However, it is very much expected that the semester program or the learning-teaching process will change the result of this pretest. Of the 30 test items administered to the students, the following table shows the result.

Table 1. Percentage of Correct Answer

\begin{tabular}{|l|c|l|}
\hline Name of the Test & Number of the Students & Correct Answer \\
\hline $\begin{array}{l}\text { Pretest: } \Sigma 226 \\
\text { Mean }=9.04\end{array}$ & $\begin{array}{l}40-43 \%(12-13 \text { correct } \\
\text { answer) } \\
\text { below 36\% (below } 11 \\
\text { correct answer) }\end{array}$ \\
\hline $\begin{array}{l}\text { Posttest: } \Sigma 225 \\
\text { Mean }=9.00\end{array}$ & $4(16 \%)$ & $\begin{array}{l}40-43 \%(12-13 \text { correct } \\
\text { answer) } \\
\text { below 36\% (below } 11 \\
\text { correct answer) }\end{array}$ \\
\hline
\end{tabular}

From the table above, it can be seen that there is no increase, but decrease of the learning achievement. The six students (24\%) who can answer $40-43 \%$ correctly of the pretest decrease to four students $(16 \%)$ with the same percentage in the posttest. Those who answer below $36 \%$ of the pretest increase insignificantly from 19 students $(76 \%)$ to 21 students $(84 \%)$ within the same percentage. This means the number of the students who can answer $40-43 \%$ of the pretest decreases in the posttest, likewise the number of the students who can answer only $36 \%$ of the pretest increases insignificantly in the posttest from 19 students (76\%) to 21 students $(84 \%)$. However, no increase or improvement can be seen in the correct answer. This is indicated by the mean score in the pretest 9.04 , and 9.00 in the 
posttest. In short, the learning-teaching process does not give any contribution to the learning achievement. This is really disappointing since the pretest and the posttest are the same without any changes at all. But the fact is the result of the posttest is a bit lower than that of the pretest. It should have been higher than the result of the pretest due to the learning for one semester. That learning should give impact on the result of the posttest, otherwise it does not work as it is expected. Consequently, the learning achievement previously intended cannot be reached.

A lot of questions can be raised, and the most important and apparent of all is the learning-teaching process for one semester. What materials are taught to the students? How are they taught? Do the students' attendance adequately comply with the requirements of lecture attendance? Are the students regularly given assignments? And are they returned and discussed in the classroom as a feedback? Such questions above are necessarily raised in order to trace why there is no impact of learning on the posttest after one semester program.

Perhaps, it is of importance to see how the students answer the pretest and posttest, and to observe if there is an increase in answering the test items correctly both in the pretest and posttest.

Table 2. Total Correct Answer in the Pretest and Posttest

\begin{tabular}{|c|c|c|c|}
\hline $\begin{array}{l}\text { Student } \\
\text { No. }\end{array}$ & School Origin & Pretest & Posttest \\
\hline 1 & State & 13 & 9 \\
\hline 2 & Private & 13 & 8 \\
\hline 3 & Private & 12 & 9 \\
\hline 4 & State & 12 & 7 \\
\hline 5 & State & 12 & 12 \\
\hline 6 & State & 12 & 9 \\
\hline 7 & Private & 11 & 9 \\
\hline 8 & Private & 11 & 9 \\
\hline 9 & Private & 10 & 13 \\
\hline 10 & Private & 10 & 9 \\
\hline 11 & Private $\mathrm{d}$ & 9 & 8 \\
\hline 12 & Private & 9 & 8 \\
\hline 13 & State & 9 & 8 \\
\hline 14 & Private & 9 & 10 \\
\hline 15 & State & 9 & 6 \\
\hline 16 & Private & 8 & 9 \\
\hline 17 & Private & 8 & 9 \\
\hline 18 & Private & 8 & 13 \\
\hline 19 & State & 7 & 10 \\
\hline 20 & State & 7 & 6 \\
\hline 21 & Private & 6 & 8 \\
\hline 22 & State & 6 & 12 \\
\hline 23 & State & 5 & 5 \\
\hline 24 & State & 5 & 10 \\
\hline 25 & State & 5 & 9 \\
\hline
\end{tabular}


From this table it can be seen that only 6 students (24\%) made an increase from the pretest to the posttest though it is not significant. On the contrary, fourteen students $(46,6 \%)$ made a decrease from the pretest to the posttest within average of $40 \%$. The rest remain the same, or increase insignificantly. Frankly, a decrease occurs in the posttest although it is not significant. But since the result of pretest does not reach the target either, then there seems no significant difference between the two. There should have been a significant difference between the result of the pretest and that of the posttest if the learning-teaching process had run well. That is the only most apparent factor which makes the result of the posttest similar to that of pretest as facilities, motivation, lecturer, etc.

From the result, it is known that mean score of the pretest is 9.04, and that of the posttest is 9.00. There is hardly any difference between the two, even the mean score of the posttest is a bit lower than that of the pretest. With this unchanged mean score from the pretest to the posttest, it indicates the students' ability in doing the test remains the same although they have studied more about English grammar for one semester. They got nothing about English grammar during the semester program because the result of the posttest is just like that of the pretest. The learning-teaching process should have contributed something to the posttest in the sense that their ability is higher in doing the posttest than in that doing the pretest. The only one visible and apparent factor which refers to this result is the learningteaching process. If the learning-teaching process during the semester works well as it is expected, then the result of the posttest will be better than that of the pretest. On the contrary, if the learning-teaching process during the semester does not work well, then the result of the posttest is the same as that of the pretest, or even worse.

The result of pretest of the state school students on English grammar and that of private school students do not show any difference. One is not more competent than the other on English grammar. This can be seen from the result of the pretest in which the mean score of state school students is 8.5 , whereas that of private school students is 9.54 . These two mean scores are not at all significantly different. They are in fact below the average which should be above 15 correct from thirty test items. The graduates of state school are not better than those of private school. At least in English grammar, both graduates are below average because they can only achieve around $28 \%$ to $31 \%$ of the total test with means score 8.5 to 9.54 respectively.

The mean score of posttest of both groups does not indicate significant difference either between 8.58 for the state school students and 9.31 for private school students. No matter how bad the raw input is, but after one semester of studying there should be a significant change from the beginning (pretest) to the end (posttest). In short, both groups, those from state school and those from private school, remain the same.

\section{Aspect of Grammar}

Below is the table showing test items that are correctly answered only by mostly fewer than ten students.

Table 3. Number of Correct Answers Based on Grammatical Aspect PRETEST

\begin{tabular}{|l|l|c|c|c|c|c|}
\hline Item & Aspect & Correct & Percentage & Item & Correct & Percentage \\
\hline 1 & Pronoun & - & - & 1 & 6 & 24 \\
\hline
\end{tabular}


KAIROS ELT JOURNAL, Vol. 4 No. 3 Desember 2020

Copyright $\bigcirc 2020$, ISSN: $2580-4278$

\begin{tabular}{|l|l|c|c|c|c|c|}
\hline 5 & Participle & 2 & 8 & 5 & 1 & 4 \\
\hline 6 & Passive & 4 & 16 & 6 & 6 & 24 \\
\hline 7 & Adjective & 1 & 4 & 7 & 5 & 20 \\
\hline 11 & Adjective & 8 & 32 & 11 & 8 & 32 \\
\hline 12 & Adjective & 1 & 4 & 12 & 4 & 16 \\
\hline 13 & Adjective & 4 & 16 & 13 & 3 & 12 \\
\hline 8 & Elliptic & 8 & 32 & 8 & 9 & 36 \\
\hline 9 & Elliptic & - & - & 9 & 6 & 24 \\
\hline 10 & To infinitive & 8 & 32 & 10 & - & - \\
\hline 24 & To infinitive & - & - & 24 & 7 & 28 \\
\hline 14 & Adverb & 5 & 20 & 14 & 6 & 24 \\
\hline 16 & Relative Pronoun & 9 & 36 & 16 & 9 & 36 \\
\hline 17 & Causative & 1 & 4 & 17 & 2 & 8 \\
\hline 22 & Causative & 5 & 20 & 22 & 0 & 0 \\
\hline 18 & Conditional & 5 & 20 & 18 & 4 & 16 \\
\hline 20 & Conditional & 5 & 20 & 20 & 3 & 12 \\
\hline 21 & Conditional & 6 & 24 & 21 & - & - \\
\hline 29 & Conditional & 8 & 32 & 8 & - & - \\
\hline 19 & Question tag & 4 & 16 & 19 & 8 & 32 \\
\hline 23 & Gerund & 10 & 40 & 23 & - & - \\
\hline 28 & Gerund & 4 & 16 & 28 & 10 & 40 \\
\hline 30 & Tense & 0 & 0 & 30 & 6 & 24 \\
\hline 25 & Comparative & 7 & 28 & 25 & 6 & 24 \\
\hline 26 & Word order & 9 & 36 & 26 & 5 & 20 \\
\hline & & & & & & \\
\hline
\end{tabular}

From the table above, it can be seen that there are only two topics, namely possessive item 3 and conjunction item 27, which the students answered above $40 \%$ correctly both in the pretest and posttest. That is why they are not included in the table because more than half of the students can answer them correctly. The symbol (-) in the table indicates that the correct answer is above ten students, and they are not included in this table.

Table 4. The Increase and Decrease of Correct Answer

\begin{tabular}{|l|l|l|c|}
\hline No. & Category & Number of Items & Percentage \\
\hline 1 & Increase & 13 & $16 \%-40 \%$ \\
\hline 2 & Decrease & 10 & $50 \%-12 \%$ \\
\hline 3 & Remain & 2 & $8 \%$ \\
\hline
\end{tabular}

There is no significant increase of correct answer from the pretest to the posttest with percentage of $16 \%$ up to $40 \%$ but the most is below $30 \%$. This means if there are four students, for example, answer test item 6 correctly in the pretest, then in the posttest it becomes six students as well $(16 \% \rightarrow 24 \%)$. This increase does not give much difference in learning achievement on the whole.

On the other hand, the decrease of correct answer from the pretest to posttest happens the most highly with three test items $(9,22$, and 24) in which the percentage reaches $50 \%$ and higher. 
Since there are 30 test items administered to the students both in the pretest and the posttest, and 25 test items need analyzing because they do not show any difference from the pretest to the posttest as they are presented above. Then, what happens to the other five items left? They are not included in the previous table since the number of the students who answer them correctly reaches above ten students. The five test items are presented below.

Table 5. Test Items with High Correct Answers

\begin{tabular}{|c|l|c|c|c|c|c|}
\hline & & \multicolumn{2}{|c|}{ PRETEST } & \multicolumn{3}{c|}{ POSTTEST } \\
\hline Item & Aspect & Correct & Percentage & Item & Correct & Percentage \\
\hline 2 & adverb & 17 & 68 & 2 & 17 & 68 \\
\hline 3 & Possessive & 18 & 72 & 3 & 17 & 68 \\
\hline 4 & Tense & 11 & 44 & 4 & 12 & 48 \\
\hline 15 & Pronoun & 15 & 60 & 15 & 14 & 56 \\
\hline 27 & Conjunction & 15 & 60 & 27 & 12 & 48 \\
\hline
\end{tabular}

From the table above, it can be seen three test items $(3,15,27)$ have a decrease from the pretest to the posttest within $4 \%$ to $12 \%$. It means if there are 18 correct answer in the pretest, it decreases to 17 correct answer in the posttest. While item 2 remains the same from the pretest to the posttest concerning the correct answer. Test item 4 increases from 11 correct answer in pretest to 12 correct answer in the posttest, but not significantly. In short, it can be concluded that both the increase and decrease of the correct answer do not show significant difference between the result of the pretest and that of the posttest.

D.Conclusions

Some conclusions can be drawn based on the result and findings.

(1) There is no difference between the result of the pretest, and that of the posttest. This is indicated by the mean score of the pretest 9.04, and that of the posttest 9.00. It implies that the learning-teaching process does not work well as it is expected.

(2) Those students of state school are not different from those students of private school in the grammar of English. This is indicated by the mean score 8.5 of the state school students in the pretest, and 9.54 of the private school students in the same test. This means that their ability on English grammar is not different.

(3) After studying for one semester about grammar of English, both students of state school and those of private school do not show any difference of their ability on English grammar. Based on the posttest, it is clear that the mean score of state school students is 8.58, and that of private school is 9.31 .

(4) Of the 30 test items administered both in the pretest and posttest, 25 test items have no significant increase of correct answer from the pretest to the posttest. As for the 5 items though the correct answer are a bit $50 \%$ of the total students in the pretest, they do not increase significantly in the posttest. Of the 17 topics in the test, only a few can be correctly answered by a bit more than $50 \%$ of the students but they tend to decrease in the posttest. Topics concerning adjective, causative, passive, infinitive and elliptic are the most difficult items for the students though other topics are not satisfactory either. 
(5) It is obvious that the learning-teaching process in the classroom does not work well as it is expected because it cannot enhance the learning achievement from the pretest to the posttest. It is the main factor which makes no difference between the result of the pretest and the posttest, and obviously the faculty staff who is in charge of this subject is decently questionable.

\section{BIBLIOGRAPHY}

Akmajian, Adrian, et.al 1991. Linguistics: Introduction to Language and Communication. Boston: Massachusetts Institute of Technology

Davis, Robert A. 1966. Learning in the School. Belmont: Wardswoorth Publishing Company, Inc.

Fitikides, T.J. 1963. Common Mistakes in English. Hong Kong: Longman Group

Gagne, Robert M.1974. Essentials of Learning for Instruction. New York: Holt, Rinehart and Winston.

Gethin, Hugh. 1988. Grammar in Context. London: Collins ELT.

Hatch, Evelyn and Hossen Farhady. 1982. Research Design and Statistics for Applied Linguistics. Rowley: Newbury House Publishers, Inc.

Hendrojuwono,Wisnubraa.1982. "PengantarPsikology Belajar” dalam Materi Dasar Pendidikan Program Bimbingan dan Konseling di Perguruan Tinggi, Buku IIc Psikolgi Belajar. Jakarta: Depdikbud.

I.Wayan, Ardhana.1984. PengantarTeknology Pendidikan Proyek Pengajarn Sistem Pendidikan. Jakarta: Depdikbud

O’Grady,William and Michael Dobrovolsky. 1989. Contemporary Linguistics: An Introduction. NewYork: St.martin Press.

Richards, Jack, et.al 1985. Longman Dictionary of Applied Linguistics. Essex: Longman Group, Ltd

Seely, John. 2000.The Oxford Guide to Writing and Speaking. Oxford: Oxford University Press.

Sharp, Vicki F. 1979.Statistcs for the Social Sciences. Boston: Little, Brown and Company

Sumiati, Ibnu Umar. 1982. "Faktor-Faktor yang Mempengaruhi Proses Belajar dan Prestasi Belajar" dalam Materi Dasar Pendidikan Progam Bimbingan dan Konseling di Perguruan Tinggi Buku IIc Psikologi Belajar. Jakarta: Depdikbud 
KAIROS ELT JOURNAL, Vol. 4 No. 3 Desember 2020

Copyright $\bigcirc 2020$, ISSN: 2580-4278

Veit, Richard. 1986. Discovering English Grammar. Boston: Houghton Mifflin Company.

Wekker, Herman and Liliane Haegeman.1996: A Modern Course in English Syntax. London:Routletdge

Winkel, W.S.1986. Psikologi Pendidikan dan Evaluasi Belajar. Jakarta: PT.Gramedia. 